Caso clínico

\title{
Síndrome de inmunodeficiencia común variable a propósito de un caso
}

\author{
Common Variable Immunodeficiency Syndrome, a clinical case and literature \\ revision
}

Teresa Mendoza Altuna

Médico Residente $4^{\circ}$ de Medicina del Trabajo del Hospital Universitario de Cruces. Vizcaya. España.

Recibido: 18-10-13

Aceptado: 22-10-13

\section{Correspondencia}

Teresa Mendoza Altuna

Unidad Básica de Prevención

Hospital Universitario Cruces

Plaza de Cruces s/n 48903 Barakaldo

Vizcaya. España.

Tlfno. 689518781

E-mail: temeal@hotmail.com

Med Segur Trab (Internet) 2013; 59 (233) 444-446

Resumen

La inmunodeficiencia común variable (IDCV) es la inmunodeficiencia primaria que con más frecuencia encontramos en la práctica clínica. Clínicamente se define como la presencia de infecciones recurrentes y una reducción en suero de IgG (al menos 2 desviaciones estándar por debajo de los valores de referencia para su edad) y al menos otra de las $\operatorname{Ig}(\operatorname{IgA}$ o IgM) y una reducción o ausencia de producción de anticuerpos

La clínica que presentan estos pacientes son múltiples infecciones pulmonares, infecciones bacterianas sistémicas y complicaciones gastrointestinales, siendo las infecciones la manifestación clínica más frecuente. Se conoce muy poco acerca de los mecanismos etiopatogénicos que conducen a esta anormalidad inmunológica.

Presentamos un caso de IDCV en una trabajadora sanitaria pretendiendo revisar los síntomas del cuadro clínico así como hacer una reflexión sobre los efectos de la prevención de riesgos para el trabajador.

Palabras clave: Inmunodeficiencia común variable. IDCV. Infecciones pulmonares.

Abstract

Common variable immunodeficiency (CVID) is the primary immunodeficiency frequently found in the clinical practice. Clinically, it is defined as the presence of recurrent infections and a reduction in IgG serum (at least 2 standard deviations before the reference values for the subject's age) and at least another one of the Ig (IgA or IgM) and a reduction or absence of the production of antibody.

The clinical manifestations of these patients are multiple pulmonary infections, systemic bacterial infections and gastrointestinal complications, the pulmonary infections being the clinical manifestations found most. Very little is known about the a etiopathogenic mechanism leading to this immunological abnormality.

Here we present a case of CVID in a health worker pretending to review the clinical symptoms, as well as to think about the effects of prevention of occupational hazards.

Key words: Common variable immunodeficiency. CVID. Immunoglobulins, pulmonarary infections. 


\section{ANTECEDENTES}

Como parte del Procedimiento de Vigilancia de la Salud así como del Protocolo de Seguimiento de la Enfermedad Común existente en el Sistema de Gestión de Prevención de Riesgos Laborales (SGPRL) implantado en Osakidetza-Servicio Vasco de salud, que tiene entre otros como objetivo prever la adaptación de un trabajador cuyas características personales o el estado biológico conocido lo hagan sensible a las condiciones del puesto de trabajo, es atendida en la consulta de la Unidad Básica de Prevención (U.B.P.), una trabajadora en situación de IT con el fin de valorar aptitud para reincorporación a su puesto de trabajo.

\section{DESCRIPCIÓN DEL CASO}

Trabajadora de este Hospital de 54 años, asignada al Bloque Quirúrgico como Auxiliar de Enfermería.

Cuadro de inicio en el año 2012, refiriendo diarrea de año de evolución que fue estudiada por Digestivo descartándose Enfermedad de Crohn y/o Enfermedad Inflamatoria Intestinal, la cual remite con tratamiento de corticoides. Durante el estudio se identifica disminución de Inmunoglobulinas, por lo cual se deriva al servicio de Medicina Interna, confirmándose el hallazgo previo con una disminución de Ig M, Ig G e Ig A, así como una ausencia de linfocitos $\mathrm{B}$ de memoria. No existen hallazgos relevantes en exploración física y se realizaron los siguientes estudios complementarios:

- Laboratorio: Los resultados de Bioquímica, Hematimetría, Iones y pruebas de función hepática y renal normales. Proteinograma se identifica Ig G 937, subclases conservadas, Ig A 21, Ig M menor de 17, Ig E indetectable.

- Estudio de poblaciones linfocitarias: linfopenia B relativa sin linfocitos B de memoria funcional. Linfocitos $\mathrm{T}$ con inversión del cociente CD4/CD8 Fenotipo compatible con Inmunodeficiencia común variable.

En enero del 2013 hospitalizada por episodio de Neumonía con Insuficiencia respiratoria sin aislamiento bacteriológico. No constan en su historial ingresos o consultas previas por procesos respiratorios o digestivos. En marzo del 2013 nuevo ingreso por coledocolitiasis que precisó de intervención quirúrgica en abril del 2013.

El cuadro es compatible con una Inmunodeficiencia Común Variable por lo que se inicia tratamiento con inmunoglobulinas intravenosas a dosis de $0,4 \mathrm{~g} / \mathrm{kg}$ de peso mensual con buena tolerancia.

\section{DISCUSIÓN}

La Inmunodeficiencia Común Variable (IDCV), también llamada hipogammaglobulinemia adquirida, es la deficiencia primaria de anticuerpos más frecuente. La IDCV está caracterizada por infecciones bacterianas recurrentes, especialmente de las vías aéreas superiores e inferiores, y también asociada a incremento de la incidencia de enfermedades autoinmunes y neoplasias. La IDCV aparece a cualquier edad después de una función aparente normal del sistema inmune, la edad de aparición de los síntomas es variable, siendo más común su presentación entre los 15 y 40 años de edad $^{1-3}$.

Esta enfermedad probablemente resulta a partir de una alteración no definida de las células linfoides, resultando en el fracaso de la diferenciación de las células $\mathrm{B}$ con un déficit en la secreción de inmunoglobulinas ${ }^{2-4}$. 
El criterio diagnóstico se encuentra por los hallazgos analíticos de hipogammaglobulinemia menos de 2 DS debajo de la media para la edad, disminución de la proliferación de células T CD4/CD5, respuesta pobre o ausente a la inmunización ${ }^{3}$.

En nuestro caso el diagnóstico fue confirmado también por la deficiencia de todos los tipos de clases de inmunoglobulinas. La mayoría de estos pacientes tienen números normales de linfocitos B que pueden ser fenotípicamente inmaduros. Los linfocitos B son capaces de reconocer antígenos y pueden proliferar en respuesta a estos antígenos, pero dejar de diferenciarse para convertirse en células plasmáticas ${ }^{4}$.

En los adultos que presentan infecciones pulmonares crónicas con bronquiectasias inexplicables es importante tener en cuenta el diagnóstico de la IDCV ${ }^{3,4}$. Nuestra paciente no tenía antecedentes de ataques recurrentes de las vías respiratorias ni infecciones del tracto inferior. Cerca del $20 \%$ de los pacientes con IDCV presentan enfermedades intestinales, que incluyen la enfermedad inflamatoria intestinal, giardiasis crónica, la amebiasis, mala absorción intestinal, gastritis atrófica entre otras, como observamos en nuestro caso $^{3,5}$.

La evidencia del uso con Inmunoglobulina subcutánea como parte del tratamiento para IDCV ha demostrado que disminuye la progresión de la enfermedad pulmonar crónica, la frecuencia de neumonía y sepsis, disminuyendo el número de hospitalizaciones y el uso de antibióticos entre otros ${ }^{1,3,6}$.

En dosis apropiadas, la sustitución de Inmunoglobulina reduce la incidencia de infecciones bacterianas agudas, sin embargo, la Ig no aborda la más problemática de las complicaciones que han surgido ahora como las preocupaciones más importantes, incluyendo la enfermedad pulmonar crónica, enfermedad granulomatosa sistémica, autoinmunidad, hiperplasia linfoide enfermedad gastrointestinal y el desarrollo de neoplasias $^{7,8}$. Estas complicaciones ahora parecen ser la principal causa de morbilidad y mortalidad en pacientes con IDCV que como médicos del trabajo debemos conocer para elaborar estrategias de seguimiento en la vigilancia de la salud.

Los pacientes con IDCV presentan por lo general la falta de respuestas de Ig G (no alcanzar los niveles de protección de laboratorio definidos) a 2 o más vacunas de proteínas, tales como el tétanos o la difteria toxoides, Haemophilus, el sarampión, las paperas, la rubéola, y neumococo ${ }^{7,8}$. De ahí la importancia de conocer el estado de inmunización y la actualización del mismo previo a la incorporación al puesto de trabajo. La trabajadora aún continúa presentando Ac HVB. La mayoría de los pacientes con IDCV pueden llevar a cabo todas las actividades normales, y muchos son tratados en los programas de atención ambulatoria. Los pacientes estables deben ser vistos en intervalos mínimos anuales, y los que tienen las complicaciones mencionadas a intervalos más cortos, como por ejemplo de 3 a 6 meses. En la literatura revisada se describe un modelo sugerido para el seguimiento de pacientes con esta afectación donde debe incluirse analítica de rutina anual y seguimiento del estado inmunológico ${ }^{8}$.

Desde la Unidad Básica de Prevención se recomienda el mantener el puesto actual (Bloque Quirúrgico), por entender que supone un menor riesgo de contagio de infecciones del aparato respiratorio, debiendo evitarse la ubicación en áreas de trabajo de contacto de pacientes críticos o que supongan posibilidad de infecciones agudas de la vía respiratoria u otro tipo de patología infectocontagiosa como constituyen los servicios de: Urgencias Generales, Unidades de Cuidados Intensivos, Neumología, Pediatría y sus áreas afines, Lesionados Medulares, Consultas externas; asimismo se debe evitar la ubicación de puestos de trabajo en zonas de exposición de agentes químicos o citostáticos, puesto que se desconoce si estos agentes pueden aumentar el riesgo del desarrollo de neoplasias para estos pacientes.

En conclusión, el Síndrome de Inmunodeficiencia Común Variable es un trastorno de inmunodeficiencia primaria rara que representa un reto diagnóstico. En la mayoría de los casos el indicio es clínico y precisa un seguimiento multidisciplinar con una vigilancia de salud que permita la continuidad en su vida laboral. 


\section{BIBLIOGRAFÍA}

1. Schroeder HW Jr, Schroeder HW 3rd, Sheikh SM. The complex genetics of common variable immunodeficiency. J Investig Med 2004; 52: 90-103.

2. Hammarström L, Vorechovsky I, Webster D. Selective IgA deficiency (SIgAD) and common variable immunodeficiency (CVID). ClinExp Immunol 2000; 120: 225-231.

3. Blancas-Galicia L, Ramírez-Vargas NG, Espinosa-Rosales F. Inmunodeficiencia común variable.Enfoque clinic. Rev Invest Clin. 2010 Nov-Dec;62(6):577-82.

4. Martínez I.,Ferreiro O. Déficit selectivo de IgA e Inmunodeficiencia común variable: Reporte de cinco casos. Inmunología. Abril-Junio 2010. Vol. 29 / Núm 2: 66-73

5. Arzu Didem Yalcin, Nese Aydemir, et all. Common variable immunodeficiency syndrome with right aortic arch: a case report. BMC Infectious Diseases 2004, 4:2

6. Branka Filipović, Zorica Šporčić, et all. Common Variable Immunodeficiency Associated with Inflammatory Bowel Disease and Type I Diabetes. Notas Clínicas 2009:2 67-71.

7. Hassan Abolhassani, Babak Torabi Sagvand,et all. A review on guidelines for management and treatment of common variable immunodeficiency. Expert Rev. Clin. Immunol. 2013 9(6): 561-575

8. Cunningham-Rundles C.How I treat common variable immune deficiency. Blood. 2010 Jul $8 ; 116(1): 7-15$.

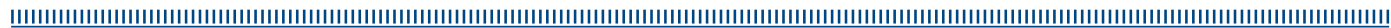

